\title{
Toxicity of Checkpoint Inhibition in Advanced RCC: A Systematic Review
}

\author{
Moshe C. Ornstein ${ }^{\mathrm{a}, *}$ and Jorge A. Garcia ${ }^{\mathrm{a}, \mathrm{b}}$ \\ ${ }^{a}$ Cleveland Clinic Taussig Cancer Institute, Cleveland, $\mathrm{OH}$, USA \\ ${ }^{\mathrm{b}}$ Cleveland Clinic Glickman Urological and Kidney Institute, Cleveland, OH, USA
}

\begin{abstract}
.
Background: Checkpoint inhibitors (CPI) have now been established as standard agents in the management of patients with metastatic renal cell carcinoma (mRCC). Given the unique toxicity profiles of CPIs, a detailed understanding of their incidence rate and characteristics is critical.

Objective: To perform a systematic review for the analysis of the incidence rate and characteristics of toxicities in mRCC patients treated with CPIs in published clinical trials.

Methods: A systematic search of EMBASE (Ovid) and MEDLINE (Ovid) was conducted as per PRISMA guidelines to identify prospective clinical trials of checkpoint inhibitors in $\mathrm{mRCC}$. The search method involved querying for the terms renal cell carcinoma or kidney carcinoma with any of the following: programmed cell death 1,PD-1, programmed cell death ligand 1, PD-L1, cytotoxic T-lymphocyte antigen 4, CTLA-4, immunotherapy, checkpoint inhibitor, anti-PD-1, or anti-PD-L1. Only prospective clinical trials were included.

Results: The systematic review yielded 9,722 records through the MEDLINE (Ovid) and EMBASE (Ovid) databases. Ultimately, five prospective clinical trials with 722 patients were selected for inclusion. The rates of any grade adverse event (AE) and grade (G) 3-4 AEs were 79.9\% and 20.9\%, respectively. Regarding immune-related AEs (irAEs), the most common system affected by any grade irAE was the skin $(30.89 \%)$ and the most common grade 3-4 irAE was related to the hepatic system (8.23\%). Rates of AEs were similar across the CPI monotherapy clinical trials.

Conclusions: The rates of AEs in mRCC patients treated with CPI is similar to rates in other cancers. AEs in mRCC are fairly consistent among monotherapy trials with PD-1 and PD-L1 inhibitors and as one would expect higher when CTLA-4 and PD-1 inhibitors are offered in combination.
\end{abstract}

Keywords: Renal cell carcinoma, kidney carcinoma, immunotherapy, checkpoint inhibitors, PD-1, PD-L1, CTLA-4, immune-related adverse events, toxicity

\section{INTRODUCTION}

Checkpoint inhibitor (CPI) immunotherapy, which primarily target the inherent immune inhibitory

\footnotetext{
*Correspondence to: Moshe C. Ornstein, MD, MA, Associate Staff, Genitourinary Oncology, Cleveland Clinic Taussig Cancer Institute, 9500 Euclid Ave, CA-60, Cleveland, OH 44195, USA. Tel.: +1 216444 6592; Fax: +1 216444 9464; E-mail: ornstem@ccf.org.
}

signals programmed cell death (PD-1), programmed cell death ligand 1 (PD-L1), and cytotoxic $\mathrm{T}$ -Lymphocyte associated protein 4 (CTLA-4), have revolutionized the therapeutic landscape across many solid tumors [1-3]. A primary challenge in the era of CPI therapy revolves around the balance of efficacy and toxicity of these novel agents. Although their overall toxicity profile is favorable when compared to standard anti-cancer agents such 
as chemotherapy and targeted therapy [4-6], the immune-based mechanism of CPIs results in a novel toxicity profile that differs from traditional cytotoxic therapies [7].

The inherent immunogenic nature of renal cell carcinoma (RCC) has cemented its place at the forefront of cancer immunotherapy. Nivolumab (anti-PD-1) is currently approved for patients with metastatic RCC (mRCC) who have been previously treated with VEGF-TKI based therapy [4]. Similarly, phase III data of the combination of nivolumab and ipilimumab (anti-CTLA-4) has demonstrated overall survival (OS) superiority to a current standard of care [8]. A plethora of phase III trials are also underway investigating the use of novel combinations of CPI and targeted therapies [9-12]. A better understanding of these AEs and their management is critical for practicing physicians as the use of these novel agents is expanding across different stages of RCC.

Given the multitude of CPIs with clinical activity in mRCC, an analysis of CPI-induced toxicities is essential. To date, multiple case reports and case series have been published describing AEs related to these agents $[13,14]$. In this systematic review, we evaluate the incidence rate and characteristics of toxicities in mRCC patients treated with CPI therapy in published clinical trials.

\section{METHODS}

\section{Search methods}

A systematic review of the literature was conducted according to the guidelines outlined in the Preferred Reporting Items for Systematic Reviews and Meta-Analyses (PRISMA) statement [15]. The PUBMED (Ovid) and EMBASE (Ovid) databases were searched up to September 1, 2017. The search method involved querying for the terms renal cell carcinoma or kidney carcinoma with any of the following: programmed cell death 1,PD-1, programmed cell death ligand 1, PD-L1, cytotoxic T-lymphocyte antigen 4, CTLA-4, immunotherapy, checkpoint inhibitor, anti-PD-1, or anti-PD-L1. The first stage was the selection of articles that included any combination of the aforementioned terms. The second stage involved identifying the year in which there were increasing mentions of checkpoint inhibitor terms in article titles (e.g., B7, CTLA-4). The year 2007 was thus selected as the starting point for article screening. Subsequent stages are outlined in Fig. 1.

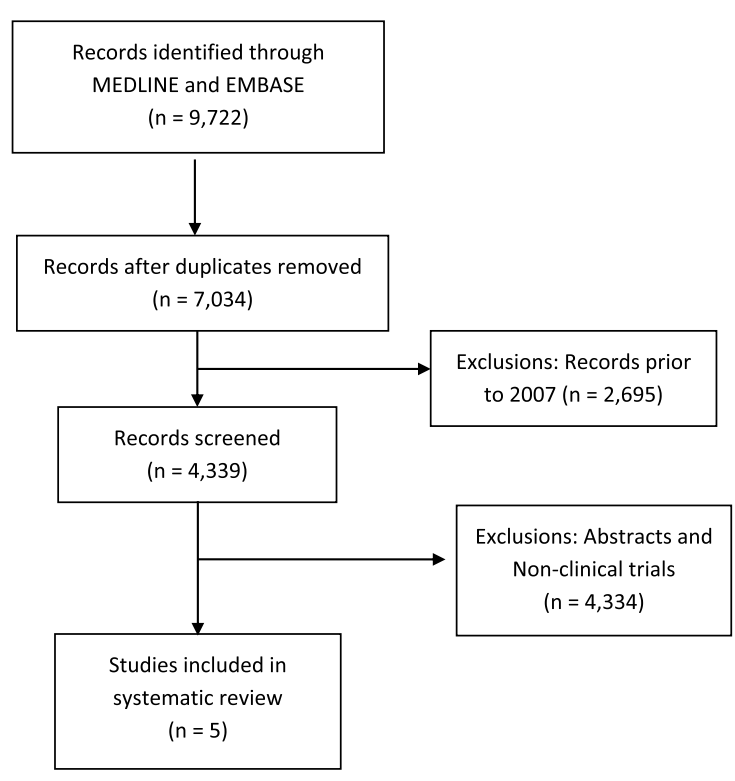

Fig. 1. Consort flow diagram of systematic review.

\section{Inclusion and exclusion criteria}

The eligibility criteria for inclusion in the systematic review included prospective clinical trials of checkpoint inhibitors in patients with mRCC. Abstracts, systematic reviews, and review articles were excluded from the analysis. The analysis was limited to articles from January 1, 2007 through September 1, 2017.

\section{Data extraction and outcome measures}

The final articles were jointly selected by the two authors who then extracted the AE data and presented them in descriptive form. Priority was given to AEs described in each of the final articles that met selection criteria. Unless otherwise noted, every AE was described in all articles reviewed.

\section{AEs and irAEs}

Adverse Events (AEs) were extracted if they were considered "treatment-related" in the respective clinical trials. Only the most common AEs in each trial were selected for inclusion in this systematic review. Immune-related adverse events (irAEs) refer to specific $\mathrm{AEs}$ assumed to be driven by immune-related processes induced by the mechanism of action of CPI therapy. Specifically, skin (rash, pruritus), endocrine (hypothyroidism), gastrointestinal (diarrhea), hepatic (elevated AST and ALT), pulmonary (pneumonitis), 
Table 1

Rates on AEs by clinical trial

\begin{tabular}{|c|c|c|c|c|c|c|}
\hline & & Nivolumab & Nivolumab & Nivolumab & Atezolizumab & $\begin{array}{l}\text { Ipilimumab } \\
+ \text { Nivolumab }\end{array}$ \\
\hline \multicolumn{2}{|c|}{ Phase } & $\mathrm{I}(18)$ & II (19) & III (4) & Ia (16) & $\mathrm{I}(17)$ \\
\hline \multicolumn{2}{|c|}{$\mathrm{N}$ (722 total) } & 34 & 168 & 406 & 70 & 94 \\
\hline \multirow{4}{*}{ Adverse Events } & All Gr & $85.29 \%$ & $72.62 \%$ & $78.57 \%$ & $84.29 \%$ & $93.62 \%$ \\
\hline & Gr 3-4 & $17.65 \%$ & $11.90 \%$ & $18.72 \%$ & $17.14 \%$ & $50.00 \%$ \\
\hline & $\begin{array}{l}\text { Discontinued } \\
\text { due to } \mathrm{AE}\end{array}$ & $14.71 \%$ & $6.55 \%$ & $7.64 \%$ & $4.29 \%$ & $19.15 \%$ \\
\hline & $\begin{array}{l}\text { Deaths due } \\
\text { to } \mathrm{AE}\end{array}$ & 0 & 0 & 0 & 0 & 0 \\
\hline \multirow[t]{2}{*}{ Pneumonitis } & All Gr & $2.94 \%$ & $4.76 \%$ & $3.94 \%$ & $2.86 \%$ & $8.51 \%$ \\
\hline & Gr3-4 & 0 & 0 & $1.48 \%$ & 0 & 0 \\
\hline \multirow[t]{2}{*}{ Fatigue } & All Gr & $2.94 \%$ & $26.79 \%$ & $33.00 \%$ & $28.57 \%$ & $58.51 \%$ \\
\hline & Gr3-4 & 0 & 0 & $2.46 \%$ & $4.29 \%$ & $3.19 \%$ \\
\hline \multirow[t]{2}{*}{ Rash } & All Gr & $26.47 \%$ & $9.52 \%$ & $10.10 \%$ & $14.29 \%$ & $28.72 \%$ \\
\hline & Gr3-4 & 0 & 0 & $0.49 \%$ & 0 & 0 \\
\hline \multirow[t]{2}{*}{ Pruritus } & All Gr & $17.65 \%$ & $10.12 \%$ & $14.04 \%$ & $11.43 \%$ & $34.04 \%$ \\
\hline & Gr3-4 & $2.94 \%$ & $0.60 \%$ & 0 & 0 & 0 \\
\hline \multirow[t]{2}{*}{ Dry skin } & All Gr & $11.76 \%$ & $6.55 \%$ & NR & $8.57 \%$ & NR \\
\hline & Gr3-4 & 0 & 0 & NR & 0 & NR \\
\hline \multirow[t]{2}{*}{ Nausea } & All Gr & $5.88 \%$ & $11.90 \%$ & $14.04 \%$ & $12.86 \%$ & $36.17 \%$ \\
\hline & Gr3-4 & 0 & $1.19 \%$ & $0.25 \%$ & 0 & $1.06 \%$ \\
\hline \multirow[t]{2}{*}{ Diarrhea } & All Gr & $17.65 \%$ & $9.52 \%$ & $12.32 \%$ & $11.43 \%$ & $35.11 \%$ \\
\hline & Gr3-4 & 0 & 0 & $1.23 \%$ & 0 & $9.57 \%$ \\
\hline \multirow[t]{2}{*}{ Elevated AST or ALT } & All Gr & $17.65 \%$ & $8.93 \%$ & NR & $2.86 \%$ & $46.81 \%$ \\
\hline & Gr3-4 & 0 & $2.38 \%$ & NR & $2.86 \%$ & $21.28 \%$ \\
\hline \multirow[t]{2}{*}{ Decreased appetite } & All Gr & $8.82 \%$ & $6.55 \%$ & $11.82 \%$ & $15.71 \%$ & $21.28 \%$ \\
\hline & Gr3-4 & 0 & 0 & $0.49 \%$ & 0 & 0 \\
\hline \multirow[t]{2}{*}{ Arthralgia } & All Gr & $8.82 \%$ & $7.74 \%$ & NR & $14.29 \%$ & $23.40 \%$ \\
\hline & Gr3-4 & 0 & $0.60 \%$ & NR & 0 & 0 \\
\hline \multirow{2}{*}{ Hypothyroidism } & All Gr & $8.82 \%$ & $5.95 \%$ & NR & $8.57 \%$ & $18.09 \%$ \\
\hline & Gr3-4 & 0 & $0.60 \%$ & NR & 0 & $2.13 \%$ \\
\hline
\end{tabular}

$\mathrm{NR}=$ Not reported.

and renal (increased creatinine) irAEs were selected for inclusion.

\section{RESULTS}

The systematic review yielded 9,722 records through the MEDLINE (Ovid) and EMBASE (Ovid) databases that met the initial search criteria. Figure 1 outlines the PRISMA consort diagram, duplicates, and excluded articles. Ultimately, only five prospective clinical trials of checkpoint inhibitors in patients with mRCC were identified and selected for inclusion. These included a phase Ia trial of atezolizumab (anti-PD-L1) [16], phase I trial of combined ipilimumab/nivolumab [17], and the phase I, II, and III trials of nivolumab in mRCC $[4,18,19]$.

A total of 722 patients were included in these five clinical trials. Table 1 highlights the most common AEs in each of the clinical trials and provides a comparison of these AEs across these trials. The largest of these five trials $(n=406)$ is the phase III trial (CheckMate025) that compared nivolumab to the
$\mathrm{m}$-TOR inhibitor evelorimus in patients with previously treated mRCC [4]. The smallest of these trials was the phase I trial of nivolumab. This expanded phase I trial of nivolumab included a total of 296 patients with various solid tumors, of which only 34 had mRCC [20]. The original manuscript did not describe toxicity based on tumor subtype and as such the data included here are from the long-term safety data of the subset of patients with mRCC [18].

Overall, highest rates of AEs were in the phase I ipilimumab/nivolumab trial [17]. In this trial, all grade AEs and G3-4 AEs were 93.6\% and 50\%, respectively (Table 1). AEs were lowest in the phase II trial (All G 72.6\%; G3-4 11.9\%), possibly due to the various dosing cohorts in the trial of nivolumab these patients received [19]. When analyzing all trials and patients included in the systematic review $(n=722)$, the rates of any AE and G3-4 AEs were $79.9 \%$ and $20.9 \%$, respectively, with only $8.8 \%$ of patients discontinuing treatment due to AEs (Table 2).

Given the expected and well-documented higher rates of AEs in patients treated with combined ipilimumab and nivolumab, Table 3 summarizes the $\mathrm{AE}$ 
Table 2

Summary of AEs in five trials included in systematic review

\begin{tabular}{|c|c|c|c|c|}
\hline & \multicolumn{2}{|c|}{ All Grade } & \multicolumn{2}{|c|}{ Gr 3-4 } \\
\hline & $\mathrm{N}$ & $\%$ & $\mathrm{~N}$ & $\%$ \\
\hline $\mathrm{N}=772$ & 617 & $79.92 \%$ & 161 & $20.85 \%$ \\
\hline Fatigue & 268 & $34.72 \%$ & 16 & $2.07 \%$ \\
\hline Elevated AST or $\mathrm{ALT}^{1}$ & 67 & $18.31 \%$ & 26 & $7.10 \%$ \\
\hline Nausea & 122 & $15.80 \%$ & 4 & $0.52 \%$ \\
\hline Pruritus & 120 & $15.54 \%$ & 2 & $0.26 \%$ \\
\hline Diarrhea & 113 & $14.64 \%$ & 14 & $1.81 \%$ \\
\hline Fevers $^{2}$ & 28 & $14.14 \%$ & 2 & $1.01 \%$ \\
\hline Rash & 103 & $13.34 \%$ & 2 & $0.26 \%$ \\
\hline Arthralgia $^{1}$ & 48 & $13.11 \%$ & 1 & $0.30 \%$ \\
\hline Decreased appetite & 93 & $12.05 \%$ & 2 & $0.26 \%$ \\
\hline Hypothyroidism ${ }^{1}$ & 36 & $9.84 \%$ & 3 & $0.82 \%$ \\
\hline Dry skin ${ }^{2}$ & 21 & $7.72 \%$ & 0 & $0.00 \%$ \\
\hline Pneumonitis & 35 & $4.53 \%$ & 6 & $0.78 \%$ \\
\hline
\end{tabular}

Discontinued due to AE $68(8.81 \%)$

Deaths due to $\mathrm{AE}$

$$
0(0 \%)
$$

${ }^{1}$ Data not reported in 1 trial. ${ }^{2}$ Data not reported in 2 trials.

Table 3

Summary of AEs, excluding ipilimumab/nivolumab clinical trial

\begin{tabular}{|c|c|c|c|c|}
\hline & \multicolumn{2}{|c|}{ All Grade } & \multicolumn{2}{|c|}{ Gr 3-4 } \\
\hline & $\mathrm{N}$ & $\%$ & $\mathrm{~N}$ & $\%$ \\
\hline $\mathrm{N}=678$ & 529 & $78.02 \%$ & 114 & $16.84 \%$ \\
\hline Fatigue & 213 & $31.42 \%$ & 13 & $1.92 \%$ \\
\hline Pruritus & 88 & $12.98 \%$ & 2 & $0.29 \%$ \\
\hline Nausea & 88 & $12.98 \%$ & 3 & $0.44 \%$ \\
\hline Diarrhea & 80 & $11.80 \%$ & 5 & $0.74 \%$ \\
\hline Rash & 76 & $11.21 \%$ & 2 & $0.29 \%$ \\
\hline Decreased appetite & 73 & $10.77 \%$ & 2 & $0.29 \%$ \\
\hline Fevers ${ }^{1}$ & 11 & $10.58 \%$ & 0 & $0.00 \%$ \\
\hline Elevated AST or $\mathrm{ALT}^{2}$ & 23 & $8.46 \%$ & 6 & $2.21 \%$ \\
\hline Arthralgia $^{2}$ & 26 & $9.56 \%$ & 1 & $0.37 \%$ \\
\hline Dry Skin ${ }^{2}$ & 21 & $7.72 \%$ & 0 & $0.00 \%$ \\
\hline Hypothyroidism $^{2}$ & 19 & $6.99 \%$ & 1 & $0.37 \%$ \\
\hline Pneumonitis & 27 & $3.98 \%$ & 6 & $0.88 \%$ \\
\hline$\overline{\text { Discontinued }}$ & \multicolumn{4}{|c|}{$50(7.37 \%)$} \\
\hline Deaths due to AE & \multicolumn{4}{|c|}{$0(0 \%)$} \\
\hline
\end{tabular}

${ }^{1}$ Data not reported in 2 trials. ${ }^{2}$ Data not reported in 1 trials.

data excluding the phase I trial combination of ipilimumab and nivolumab. When limiting the analysis to patients treated with CPI-monotherapy, the rates of any AE and G3-4 AEs were $78 \%$ and $16.8 \%$, respectively, with only $7.37 \%$ of patients discontinuing treatment due to AEs (Table 3). Interestingly, there were no reported deaths due to AEs reported in any of these trials.

Rates of irAEs in all patients $(n=722)$ are documented in Fig. 2. The most common system affected by any grade irAE was the skin (30.89\%) and the most common G3-4 irAE was related to the hepatic system (8.23\%) (Fig. 2).

\section{DISCUSSION}

Ever since the durable and complete responses to interleukin-2 (IL-2) in mRCC, immunotherapy has been investigated as a potential therapeutic intervention in patients with RCC [21-23]. Nivolumab was the first CPI approved in $\mathrm{mRCC}$ based on the phase III CheckMate-025 trial that demonstrated an OS benefit to nivolumab over everolimus in patients who received prior anti-angiogenic therapy [4]. CPIs are also poised to become a standard of care in the front-line mRCC setting, with results of a number of phase III clinical trials expected over the next few years [9-12] and with the recent results of CheckMate-214 which noted an OS benefit in intermediate and high-risk untreated $\mathrm{mRCC}$ patients receiving the combination of ipilimumab/nivolumab vs sunitinib [8]. An understanding of the rates and characteristics of AEs in mRCC patients treated with CPIs is thus critical.

In this systematic review, $\mathrm{AE}$ data from five clinical trials of CPIs in mRCC are summarized (Tables 1-3; Fig. 2). The frequency of treatment-related AEs in this systematic review of mRCC patients treated with CPIs is similar to published data of patients with melanoma who were treated with CPI therapy. In pooled analyses of melanoma patients treated with ipilimumab or nivolumab the rates of all grade AEs were $85 \%$ and $71 \%$, respectively $[24,25]$. Additionally, other systemic reviews and meta-analyses also document CPI-induced irAE rates of approximately 70-80\%, with organ-specific (e.g., skin, hepatic and pulmonary among others) breakdowns similar to those in this review [24, 26, 27]. These data suggest that irAEs are likely to be driven by therapy choice rather than underlying malignancy. As such, broad guidelines developed for the management of immune-related AEs (irAE) can be implemented across disease groups (Table 4) [28-30].

Although CPI-induced AEs vary in timing of onset and severity, most are reversible with systemic therapy and multiple published guidelines exist to facilitate best therapeutic choices [29, 31-33]. A practical consideration when treating patients with CPI therapy must include an infrastructure that allows for a close monitoring of AEs. Unfortunately, there is no specific timing as when these irAEs appear to occur. Most clinical trials and pooled analyses of CPIbased therapy suggest these events occur anywhere from weeks to years after the initiation of therapy and even after therapy cessation [24, 32]. However, there is emerging evidence that suggests that that the 


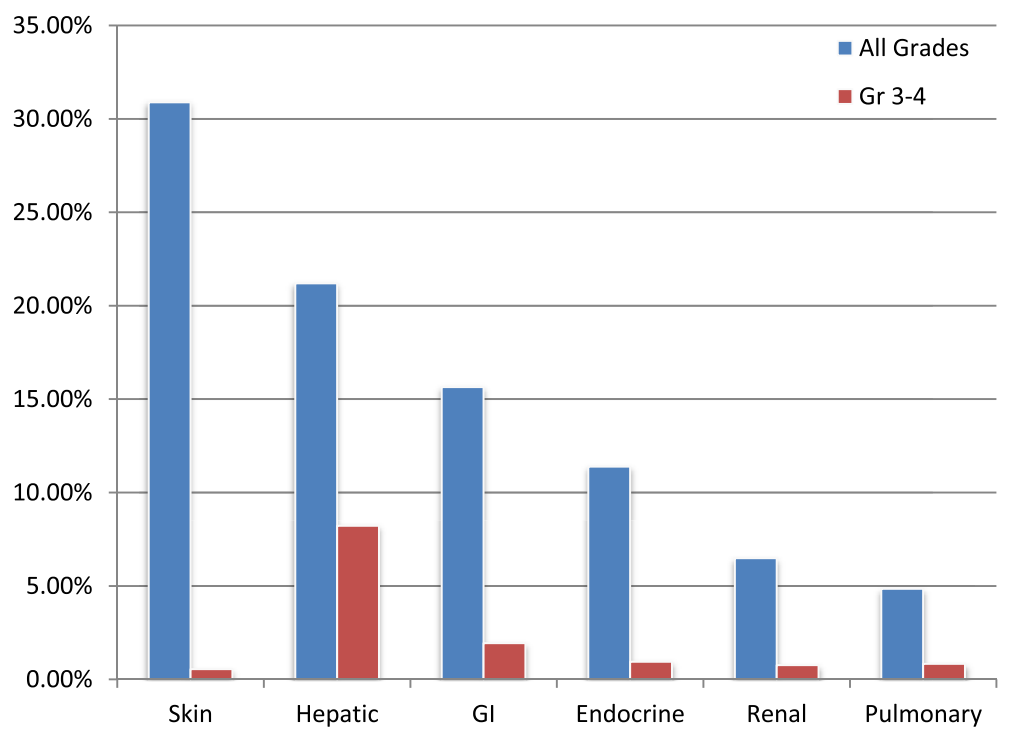

Fig. 2. Rates of select organ-specific irAEs.

majority of irAEs occur within the first year of therapy initiation and that most will fully resolve with appropriate therapy [24, 33].

Data regarding duration of irAEs are limited in the RCC literature. However, in melanoma the data suggest that most irAEs resolve within 12 weeks of onset [34]. Similarly, although most irAEs will resolve with adequate therapy, data on resuming CPIs upon irAE resolution are lacking in RCC. In an analysis of eighty melanoma patients who developed irAEs and were rechallenged with CPI therapy following irAE resolution, 31 (39\%) patients subsequently developed recurrence of initial irAE or a distinct irAE [35]. Additional data are thus needed to determine duration of irAEs and the safety of resuming CPI therapy after irAE resolution in RCC patients.

Established guidelines for the management of irAEs generally include systemic corticosteroids as the optimal primary treatment with the addition of other immunomodulatory agents such as anti-TNF- $\alpha$ for refractory irAEs [29, 32]. A theoretical concern regarding the use of systemic corticosteroids in patients receiving CPI-based therapy is that it could potentially mitigate and compromise the innate anti-tumor effect reestablished with CPI therapy. Fortunately, the use of systemic immunosuppressants does not appear to negatively impact outcome in CPI-treated patients [24, 25, 36]. In separate cohorts of melanoma patients treated with nivolumab or ipilimumab-treated melanoma patients, up to onethird of patients required systemic corticosteroid treatment and $10 \%$ also required an anti-TNF$\alpha$ agents for irAE control. Outcomes were not negatively affected by the use of systemic immunosuppressants suggesting these agents can be used without compromising clinical outcome [24, 25].

Interestingly, clinical responses appear to be sustained for a number of patients who discontinue therapy due to irAEs. In a large cohort of ipilimumabtreated melanoma patients, $12 \%$ of patients who had their CPIs discontinued due to irAEs maintained durable disease control without requiring subsequent treatment [25]. Similar findings were noted in the CPI-treated mRCC patients. In an analysis of mRCC patients treated with CPI who discontinued therapy secondary to irAEs, $44 \%$ of patients maintained a durable partial response despite not receiving subsequent therapy, with a median time from CPI discontinuation of 20 months (range, 10-44) [37].

The predictive and prognostic significance of irAEs in patients treated with immunotherapies has become an important area of discussion. The association of irAEs and response to therapy dates back to the association of specific immune-mediated AEs (e.g., hyperthyroidism and vitiligo) and clinical response to IL-2 [38, 39]. The implication of irAEs in patients treated with CPI therapy is also well documented. A number of studies demonstrate an association between the development of irAEs and clinical response to CPI therapy, specifically with ipilimumab [31, 40-42]. In a phase II trial of ipilimumab in $\mathrm{mRCC}$, the response rate was $30 \%$ in 
Table 4

Management of common irAEs ${ }^{1}$

\begin{tabular}{|c|c|c|c|c|}
\hline irAE & Gr 1 & Gr 2 & Gr 3 & Gr 4 \\
\hline Skin (rash/pruritus) & $\begin{array}{l}\text { - Continue CPI } \\
\text { - Avoid sun exposure and } \\
\text { skin irritants } \\
\text { - Topical emollients } \\
\text { - Topical steroids (mild } \\
\text { strength) +/- } \\
\text { antihistamines }\end{array}$ & $\begin{array}{l}\text { - } \text { Continue CPI } \\
\text { - Supportive care as per } \\
\text { Gr } 1 \\
\text { - Topical steroids } \\
\text { (moderate strength) +/- } \\
\text { antihistamines }\end{array}$ & $\begin{array}{l}\text { - Hold CPI } \\
\text { - Topical therapy as per } \\
\text { Gr2 } \\
\text { - Prednisolone } \\
0.5-1 \mathrm{mg} / \mathrm{kg} \text { with taper } \\
\text { over few weeks } \\
\text { - Resume CPI with irAE } \\
\text { resolution to Gr1 or } \\
\text { mild Gr2 }\end{array}$ & $\begin{array}{l}\text { - Permanently } \\
\text { discontinue CPI } \\
\text { - IV (methyl)prednisolone } \\
1-2 \mathrm{mg} / \mathrm{kg} \\
\text { - Urgent dermatology } \\
\text { review }\end{array}$ \\
\hline Hepatotoxicity & $\begin{array}{l}\text { - Continue CPI } \\
\text { - Investigate other causes } \\
\text { for hepatotoxicity }\end{array}$ & $\begin{array}{l}\text { - Hold CPI } \\
\text { - Check LFT twice } \\
\text { weekly } \\
\text { - If Gr2 LFT elevation } \\
\text { persists for } 1-2 \text { weeks, } \\
\text { start pred- } \\
\text { nisolone } 1 \mathrm{mg} / \mathrm{kg} / \mathrm{d} \\
\text { - Resume CPI following } \\
\text { LFT improvement to } \\
\text { Gr1 and steroid taper }\end{array}$ & $\begin{array}{l}\text { - Permanently } \\
\text { discontinue CPI } \\
\text { - (Methyl)prednisolone1- } \\
2 \text { mg/kg/d } \\
\text { - If no response within } \\
\text { 2-3 days, add } \\
\text { mycophenolate mofetil } \\
500 \text { mg-1 g BID } \\
\text { - Consider liver biopsy }\end{array}$ & $\begin{array}{l}\text { - Permanently } \\
\text { discontinue CPI } \\
\text { - (Methyl)prednisolone1- } \\
2 \mathrm{mg} / \mathrm{kg} / \mathrm{d} \\
\text { - Add mycophenolate } \\
\text { mofetil if no } \\
\text { improvement } \\
\text { - Consider liver biopsy }\end{array}$ \\
\hline $\begin{array}{l}\text { Gastrointestinal (diarrhea } \\
\text { or colitis) }\end{array}$ & $\begin{array}{l}\text { - Symptomatic control: } \\
\text { fluids, loperamide, etc }\end{array}$ & $\begin{array}{l}\text { - Hold CPI } \\
\text { - Prednisolone } \\
0.5-1 \mathrm{mg} / \mathrm{kg} \text { or oral } \\
\text { budesonide } \\
\text { - If no improvement, } \\
\text { proceed with sigmoi- } \\
\text { doscopy/colonoscopy }\end{array}$ & $\begin{array}{l}\text { - Discontinue CPI } \\
\text { - IV (methyl)prednisolone } \\
1-2 \mathrm{mg} / \mathrm{kg} \\
\text { - Sigmoi- } \\
\text { doscopy/colonoscopy } \\
\text { - If no improvement, add } \\
\text { infliximab }\end{array}$ & - As per Gr 3 \\
\hline Pneumonitis & $\begin{array}{l}\text { - Consider holding CPI } \\
\text { - Monitor for 2-3 days } \\
\text { - If no improvement, treat } \\
\text { as Gr } 2\end{array}$ & $\begin{array}{l}\text { - Hold CPI } \\
\text { - Rule out infection } \\
\text { - Start prednisone } \\
\text { 1-2 mg/kg (taper over } \\
\text { 4-6 weeks) }\end{array}$ & $\begin{array}{l}\text { - Permanently } \\
\text { discontinue CPI } \\
\text { - Admit to hospital } \\
\text { - Start IV } \\
\text { (methyl)prednisolone } \\
\text { 2-4 mg/kg/d } \\
\text { - Antibiotics, CT scan, } \\
\text { consider bronchoscopy }\end{array}$ & - As per Gr 3 \\
\hline
\end{tabular}

${ }^{1}$ Managment is based on ESMO guidelines (29).

patients who developed irAEs, with no responses in patients who did not develop irAEs [42]. Similarly, in a retrospective pooled analysis of 576 patients with melanoma treated with nivolumab the development of irAEs was associated with a higher objective response rate (ORR), though no PFS benefit was noted [24].

The association between clinical efficacy and irAEs has also been demonstrated in NSCLC treated with nivolumab. In a study of 134 NSCLC patients treated with nivolumab, 51\% developed irAEs. The development of irAEs was statistically significantly associated with improved PFS and OS [27]. On multivariate analysis, irAEs were independently associated with improved OS. In other analyses, irAEs were predictive of improved ORR but not OS [43]. However, it is important to note that these data are retrospective in nature and such findings have not been prospectively validated. Ultimately, the association between irAE and overall survival remains unclear, though the evidence suggests that the development of irAE at the very least does not negatively impact clinical outcomes and might predict for improved outcomes.

Although this review analyzes the currently published data of prospective clinical trials with CPI in mRCC, a remark about the future of CPI in $\mathrm{mRCC}$ and associated toxicities is critical. As previously mentioned, multiple clinical trials evaluating the combination of CPI and targeted therapy with vascular endothelial growth factor receptor (VEGFR) tyrosine kinase inhibitors (TKIs) are underway. Recently, preliminary data from the JAVELIN Renal 100 trial were reported. In this phase Ib trial of front-line axitinib (VEGFR TKI) in combination with the PD-L1 inhibitor avelumab, the vast majority of 
patients $(92.7 \%)$ reported an avelumab-related AE, the most common of which were diarrhea and fatigue (30.9\% each) [44]. A similar side effect profile was noted in the phase $1 \mathrm{~b}$ trial of the combination of pembrolizumab and axitinib [45]. It thus appears that combination therapy of CPI and VEGFR TKI will yield a similar AE profile to each drug when administered individually. Importantly, as many of the toxicities of CPI and VEGFR TKI therapy overlap, a particular clinical challenge will be determining which therapy is responsible for a specific AE. This is especially critical as AE management (e.g., use of corticosteroids, supportive care, etc.) may differ depending on the mechanism of therapy and subsequent AE. Careful clinical attention and AE monitoring will thus be critical when treating patients with combined CPI and VEGFR TKI therapy.

Importantly, this systematic review is not without some limitations. Most notably, a variety of doses were used in the phase I and II trials of nivolumab and as such the $\mathrm{AE}$ profile may not reflect that of the FDA-approved doses currently used in clinical practice. Likewise, it is expected that $\mathrm{AE}$ rates would be higher in patients receiving ipilimumab and nivolumab given the combination therapy and known toxicity profile of ipilimumab [8, 17, 33]. To correct for this concern, the AE analysis was performed including (Table 2) and excluding (Table 3) the combined ipilimumab/nivolumab trial. Other limitations include some incomplete data reported in clinical trial manuscripts and the relatively small number of published clinical trials. Also lacking is data regarding corticosteroid type, dose, and duration of therapy. Despite these limitations, this review provides a detailed overview of rates and characteristics of CPI-related toxicities in $\mathrm{mRCC}$.

\section{CONCLUSION}

As CPI therapy becomes increasingly integrated into the treatment of $\mathrm{mRCC}$, a clear understanding of their incidence, severity and optimal management are critical. In this systematic review of published clinical trials of CPIs in mRCC, the rates of AEs in mRCC patients treated with CPI appears to be fairly similar to those observed with nivolumab and atezolizumab monotherapy and higher with combined ipilimumab and nivolumab therapy. Most irAEs are reversible with systemic corticosteroids, and neither the development of irAEs nor their treatment appears to negatively impacts clinical outcome.

\section{ACKNOWLEDGMENTS}

The authors are grateful to Mary Schleicher, RN, BSN, MLIS, Medical Librarian, Floyd D. Loop Alumni Library, Cleveland Clinic, for her assistance with this systematic review.

\section{REFERENCES}

[1] Keir ME, Butte MJ, Freeman GJ, Sharpe AH. PD-1 and its ligands in tolerance and immunity. Annu Rev Immunol 2008;26:677-704.

[2] Peggs KS, Quezada SA, Korman AJ, Allison JP. Principles and use of anti-CTLA4 antibody in human cancer immunotherapy. Curr Opin Immunol 2006;18(2):206-13.

[3] Zhang T, Xie J, Arai S, Wang L, Shi X, Shi N, et al. The efficacy and safety of anti-PD-1/PD-L1 antibodies for treatment of advanced or refractory cancers: A meta-analysis. Oncotarget 2016;7(45):73068-79.

[4] Motzer RJ, Escudier B, McDermott DF, George S, Hammers HJ, Srinivas S, et al. Nivolumab versus Everolimus in Advanced Renal-Cell Carcinoma. N Engl J Med 2015;373(19):1803-13.

[5] Herbst RS, Baas P, Kim DW, Felip E, Perez-Gracia JL, Han JY, et al. Pembrolizumab versus docetaxel for previously treated, PD-L1-positive, advanced non-small-cell lung cancer (KEYNOTE-010): A randomised controlled trial. Lancet 2016;387(10027):1540-50.

[6] Cella D, Grunwald V, Nathan P, Doan J, Dastani H, Taylor F, et al. Quality of life in patients with advanced renal cell carcinoma given nivolumab versus everolimus in CheckMate 025: A randomised, open-label, phase 3 trial. Lancet Oncol 2016;17(7):994-1003.

[7] Costa R, Carneiro BA, Agulnik M, Rademaker AW, Pai SG, Villaflor VM, et al. Toxicity profile of approved anti-PD-1 monoclonal antibodies in solid tumors: A systematic review and meta-analysis of randomized clinical trials. Oncotarget 2017;8(5):8910-20.

[8] Escudier BJ, Tannir NM, McDermott DF, Frontera OA, Melichar B, Plimack ER, et al. CheckMate 214: Efficacy and safety of nivolumab + ipilimumab $(\mathrm{N}+\mathrm{I}) v$ sunitinib $(\mathrm{S})$ for treatment-naïve advanced or metastatic renal cell carcinoma (mRCC), including IMDC risk and PDL1 expression subgroups. 2017 ESMO Congress :Abstract LBA5.

[9] NCT02420821. A Study of Atezolizumab in Combination With Bevacizumab Versus Sunitinib in Participants With Untreated Advanced Renal Cell Carcinoma [IMmotion151]. 2017; Available at: https://clinicaltrials.gov/ ct2/show/NCT02420821. Accessed September 24, 2017.

[10] NCT02684006. A Study of Avelumab With Axitinib Versus Sunitinib In Advanced Renal Cell Cancer (JAVELIN Renal 101). 2017; Available at: https://clinicaltrials.gov/ct2/ show/NCT02684006. Accessed September 24, 2017.

[11] NCT02811861. Lenvatinib/Everolimus or Lenvatinib/ Pembrolizumab Versus Sunitinib Alone as Treatment 
of Advanced Renal Cell Carcinoma. 2017; Available at: https://clinicaltrials.gov/ct2/show/NCT02811861. Accessed September 24, 2017.

[12] NCT02853331. Study to Evaluate the Efficacy and Safety of Pembrolizumab (MK-3475) in Combination With Axitinib Versus Sunitinib Monotherapy in Participants With Renal Cell Carcinoma (MK-3475-426/KEYNOTE426). 2017; Available at: https://clinicaltrials.gov/ct2/show/ NCT02853331. Accessed September 24, 2017.

[13] Cappelli LC, Gutierrez AK, Baer AN, Albayda J, Manno $\mathrm{RL}$, Haque $\mathrm{U}$, et al. Inflammatory arthritis and sicca syndrome induced by nivolumab and ipilimumab. Ann Rheum Dis 2017;76(1):43-50.

[14] Jung K, Zeng X, Bilusic M. Nivolumab-associated acute glomerulonephritis: A case report and literature review. BMC Nephrol 2016;17(1):188.

[15] Moher D, Shamseer L, Clarke M, Ghersi D, Liberati A, Petticrew M, et al. Preferred reporting items for systematic review and meta-analysis protocols (PRISMA-P) 2015 statement. Syst Rev 2015;4:1-4053-4-1.

[16] McDermott DF, Sosman JA, Sznol M, Massard C, Gordon MS, Hamid O, et al. Atezolizumab, an AntiProgrammed Death-Ligand 1 Antibody, in Metastatic Renal Cell Carcinoma: Long-Term Safety, Clinical Activity, and Immune Correlates From a Phase Ia Study. J Clin Oncol 2016;34(8):833-42.

[17] Hammers HJ, Plimack ER, Infante JR, Rini BI, McDermott DF, Lewis LD, et al. Safety and Efficacy of Nivolumab in Combination With Ipilimumab in Metastatic Renal Cell Carcinoma: The CheckMate 016 Study. J Clin Oncol 2017:JCO2016721985.

[18] McDermott DF, Drake CG, Sznol M, Choueiri TK, Powderly JD, Smith DC, et al. Survival, Durable Response, and Long-Term Safety in Patients With Previously Treated Advanced Renal Cell Carcinoma Receiving Nivolumab. J Clin Oncol 2015;33(18):2013-20.

[19] Motzer RJ, Rini BI, McDermott DF, Redman BG, Kuzel TM, Harrison MR, et al. Nivolumab for Metastatic Renal Cell Carcinoma: Results of a Randomized Phase II Trial. J Clin Oncol 2015;33(13):1430-7.

[20] Topalian SL, Hodi FS, Brahmer JR, Gettinger SN, Smith DC, McDermott DF, et al. Safety, activity, and immune correlates of anti-PD-1 antibody in cancer. N Engl J Med 2012;366(26):2443-54.

[21] Fisher RI, Rosenberg SA, Fyfe G. Long-term survival update for high-dose recombinant interleukin-2 in patients with renal cell carcinoma. Cancer J Sci Am 2000;6(Suppl 1):S55-7.

[22] Rini BI, Halabi S, Rosenberg JE, Stadler WM, Vaena DA, Ou SS, et al. Bevacizumab plus interferon alfa compared with interferon alfa monotherapy in patients with metastatic renal cell carcinoma: CALGB 90206. J Clin Oncol 2008;26(33):5422-8.

[23] Mendiratta P, Rini BI, Ornstein MC. Emerging Immunotherapy in Advanced Renal Cell Carcinoma. Urol Oncol 2017;35(12):687-93.

[24] Weber JS, Hodi FS, Wolchok JD, Topalian SL, Schadendorf D, Larkin J, et al. Safety Profile of Nivolumab Monotherapy: A Pooled Analysis of Patients With Advanced Melanoma. J Clin Oncol 2017;35(7):785-92.

[25] Horvat TZ, Adel NG, Dang TO, Momtaz P, Postow MA, Callahan MK, et al. Immune-Related Adverse Events, Need for Systemic Immunosuppression, and Effects on Survival and Time to Treatment Failure in Patients With Melanoma Treated With Ipilimumab at Memorial Sloan Kettering Cancer Center. J Clin Oncol 2015;33(28):3193-8.
[26] Bertrand A, Kostine M, Barnetche T, Truchetet ME, Schaeverbeke T. Immune related adverse events associated with anti-CTLA-4 antibodies: Systematic review and metaanalysis. BMC Med 2015;13:211-015-0455-8.

[27] Haratani K, Hayashi H, Chiba Y, Kudo K, Yonesaka K, Kato R, et al. Association of Immune-Related Adverse Events With Nivolumab Efficacy in Non-Small-Cell Lung Cancer. JAMA Oncology 2017;Epub ahead of print (September 21 2017): http://jamanetwork.com/journals/ jamaoncology/fullarticle/2654556.

[28] Hahn AW, Gill DM, Agarwal N, Maughan BL. PD-1 checkpoint inhibition: Toxicities and management. Urol Oncol 2017;35(12):701-707.

[29] Haanen JBAG, Carbonnel F, Robert C, Kerr KM, Peters S, Larkin J, et al. Management of toxicities from immunotherapy: ESMO Clinical Practice Guidelines for diagnosis, treatment and follow-up. Ann Oncol 2017;28(suppl 4):iv119-iv142.

[30] Friedman CF, Proverbs-Singh TA, Postow MA. Treatment of the Immune-Related Adverse Effects of Immune Checkpoint Inhibitors: A Review. JAMA Oncol 2016;2(10): 1346-53.

[31] Beck KE, Blansfield JA, Tran KQ, Feldman AL, Hughes MS, Royal RE, et al. Enterocolitis in patients with cancer after antibody blockade of cytotoxic T-lymphocyteassociated antigen 4. J Clin Oncol 2006;24(15):2283-9.

[32] Weber JS, Kahler KC, Hauschild A. Management of immune-related adverse events and kinetics of response with ipilimumab. J Clin Oncol 2012;30(21):2691-7.

[33] Sznol M, Ferrucci PF, Hogg D, Atkins MB, Wolter P, Guidoboni M, et al. Pooled Analysis Safety Profile of Nivolumab and Ipilimumab Combination Therapy in Patients With Advanced Melanoma. J Clin Oncol 2017:JCO2016721167.

[34] Weber JS, Dummer R, de Pril V, Lebbe C, Hodi FS, MDX010-20 Investigators. Patterns of onset and resolution of immune-related adverse events of special interest with ipilimumab: Detailed safety analysis from a phase 3 trial in patients with advanced melanoma. Cancer 2013;119(9):1675-82.

[35] Pollack MH, Betof A, Dearden H, Rapazzo K, Valentine I, Brohl AS, et al. Safety of resuming anti-PD-1 in patients with immune-related adverse events (irAEs) during combined anti-CTLA-4 and anti-PD1 in metastatic melanoma. Ann Oncol. 2017 Oct 11. doi: 10.1093/annonc/mdx642. [Epub ahead of print]

[36] Harmankaya K, Erasim C, Koelblinger C, Ibrahim R, Hoos A, Pehamberger $\mathrm{H}$, et al. Continuous systemic corticosteroids do not affect the ongoing regression of metastatic melanoma for more than two years following ipilimumab therapy. Med Oncol 2011;28(4):1140-4.

[37] McKay RR, Martini D, Moreira RB, Hamieh L, Norton C, Mullane A, et al. Outcomes of PD-1/PD-L1 responders who discontinue therapy for immune-related adverse events (irAEs): Results of a cohort of patients (pts) with metastatic renal cell carcinoma (mRCC). J Clin Oncol (Meeting Abstracts) 2017;35:Asbtr467.

[38] Atkins MB, Mier JW, Parkinson DR, Gould JA, Berkman EM, Kaplan MM. Hypothyroidism after treatment with interleukin-2 and lymphokine-activated killer cells. N Engl J Med 1988;318(24):1557-63.

[39] Phan GQ, Attia P, Steinberg SM, White DE, Rosenberg SA. Factors associated with response to high-dose interleukin2 in patients with metastatic melanoma. J Clin Oncol 2001;19(15):3477-82. 
[40] Bouwhuis MG, Ten Hagen TL, Suciu S, Eggermont AM. Autoimmunity and treatment outcome in melanoma. Curr Opin Oncol 2011;23(2):170-6.

[41] Downey SG, Klapper JA, Smith FO, Yang JC, Sherry RM, Royal RE, et al. Prognostic factors related to clinical response in patients with metastatic melanoma treated by CTL-associated antigen- 4 blockade. Clin Cancer Res 2007;13(22 Pt 1):6681-8.

[42] Yang JC, Hughes M, Kammula U, Royal R, Sherry RM, Topalian SL, et al. Ipilimumab (anti-CTLA4 antibody) causes regression of metastatic renal cell cancer associated with enteritis and hypophysitis. J Immunother 2007;30(8):825-30.

[43] Judd J, Zibelman M, Handorf E, O’Neill J, Ramamurthy $\mathrm{C}$, Bentota $\mathrm{S}$, et al. Immune-Related Adverse
Events as a Biomarker in Non-Melanoma Patients Treated with Programmed Cell Death 1 Inhibitors. Oncologist 2017;22(10):1232-37.

[44] Choueiri TK, Larkin JMG, Oya M, Thistlethwaite F, Martignoni M, Nathan P, et al. First-line avelumab+axitinib therapy in patients pts) with advanced renal cell carcinoma (aRCC): Results from a phase Ib trial. J Clin Oncol (Meeting Abstracts) 2017;35:Abstr4504.

[45] Atkins MB, Plimack ER, Puzanov I, Fishman MN, McDermott DF, Cho DC, et al. Axitinib in combination with pembrolizumab in patients (pts) with advanced renal cell carcinoma (aRCC): Preliminary safety and efficacy results. ESMO Congress 2016;Abstr773. 